\title{
Programa Mais Médicos: análise das competências médicas na assistência à saúde da família
}

\author{
Juliana Goulart Soares do Nascimento.
}

\section{RESUMO}

O presente artigo tem como objetivo explicitar se há diferenças na mobilização de competências quando do exercício da profissão entre médicos do Programa Mais Médico (PMM) e médicos que não são do PMM. Tomando como referência as perspectivas de competência trazidas, o histórico da implantação do PMM no Sistema Único de Saúde e as construções históricas da profissão médica, realizou-se a definição de treze competênciaschave para os médicos que atuam na Atenção Básica. Para tanto, selecionaram-se dezenove variáveis advindas do instrumento de avaliação externa do Programa Nacional de Melhoria do Acesso e da Qualidade da Atenção Básica para analisar as competências estabelecidas, sobre as quais foram realizados testes de Qui-quadrado e teste $t$ quando possível, com uma amostra de $\mathbf{2 7 . 0 8 6}$ equipes e $\mathbf{7 8 . 8 7 5}$ usuários respondentes. Observou-se que para todas as competências analisadas houve pouca diferença entre os resultados de mobilização das equipes que possuem médicos que são do PMM e médicos que não são, com destaque para as regiões Sul e Sudeste nas análises regionais, com leve preponderância positiva dos resultados trazidos pelos médicos das equipes que não são do PMM. Isso em muito pode ser explicado, já que a amostra se refere aos ciclos iniciais do PMM e, mais do que isso, estão sendo analisadas competências pela lente das Diretrizes Curriculares Nacionais de medicina, o que permite a inferir sobre maneira como os resultados dos médicos das equipes que possuem médicos do PMM são satisfatórios.

Palavras-chave: competências, SUS, PMM. 


\section{INTRODUÇÃO}

O presente trabalho nasceu de uma inquietação sobre as discussões travadas relativas a uma recente medida tomada no âmbito do provimento de profissionais médicos no Brasil denominado Programa Mais Médicos (PMM) e sua relação à qualidade do serviço prestado a população pelos médicos deste Programa advindos de outros país frente à prestação dos serviços que os médicos brasileiros realizam.

Como alternativa encontrada para solucionar dificuldades enfrentadas pelo Sistema Único de Saúde principalmente relacionadas ao provimento de médicos para a Atenção Básica, o PMM foi criado através da Medida Provisória no621, publicada em 8 de julho de 2013 e teve sua regulamentação efetivada pela Lei $n$ o 12.871. O programa foi desenhado para abarcar resolutivas não apenas para o provimento emergencial de médicos nas áreas descobertas - tendo sido este inicialmente o grande foco e instigador dos debates sobre o programa -, mas também abarca um plano de expansão da graduação em medicina e da residência médica além de melhoria na infraestrutura das unidades básicas de saúde já existentes no país bem como a construção de novas unidades.

Quando das discussões iniciais sobre o PMM, observou-se de imediato que a grande problemática em torno do tema é se os médicos que estavam vindo de outros países estariam em condições suficientes e adequadas para realizar o atendimento à população, dado a não submissão dos diplomas dos médicos estrangeiros ao Exame Nacional de Revalidação de Diplomas Médicos Expedidos por Instituições de Educação Superior Estrangeiras (REVALIDA), instituído pelo Ministério da Educação em parceria com o Ministério da Saúde, por meio do Instituto Nacional de Estudos e Pesquisas Educacionais Anísio Teixeira (INEP), conforme disposto na Portaria Interministerial no 278/20117. Essa premissa do programa gerou grande mídia controversa sobre o mesmo na época de sua implantação e trouxe para este trabalho a inquietação de compreender quais seriam então as qualificações destes profissionais para o exercício da profissão na Atenção Básica.
Um dos pontos levantados e que alimentam o debate sobre a lógica do PMM está relacionado às competências médicas enquanto um fator significativo para a contribuição na melhoria do atendimento aos pacientes da Atenção Básica.

O tema das competências, por si só, já apresenta grande desafio quando inserido no universo das organizações privadas, que apresentam estruturas mais maleáveis para a reestruturação de processos de gestão de pessoas permitindo a troca da gestão baseada no engessamento do cargo para a amplitude da entrega permitida pelas competências. Porém, quando voltado o olhar para as organizações públicas, reconhece-se em pouco tempo os entraves legais e burocráticos de tratar os processos de gestão de seus indivíduos com a quebra das barreiras que a gestão por competências pressupõe.

Nesta perspectiva, discute-se o tema pela lógica das competências, uma área de complexas relações que possui desafios associados, por exemplo, à mensuração de resultados e seu impacto na saúde dos indivíduos; e o foco para a carreira médica, uma profissão dita "imperial", que possui elementos historicamente presentes no inconsciente coletivo e no ideário da sociedade e destes profissionais.

Como se não bastasse estas difíceis correlações, como traçar comparativos com profissionais vindo de realidades tão diferentes enquanto campo de formação e atuação? Para além de compreender a unidade de análise, ou seja, o médico, o que se buscou neste estudo foi compreender esta unidade de análise na amplitude de sua atuação no Brasil. Utilizou-se desta forma os dados do Programa Nacional de Melhoria do Acesso e da Qualidade da Atenção Básica (PMAQ), que realiza o monitoramento e a avaliação das atividades da Atenção Básica $(A B)$ no Sistema Único de Saúde (SUS).

Assim sendo, o seguinte problema de pesquisa balizou o estudo: Há diferenças na mobilização de competências quando do exercício da profissão de médicos que são do PMM e médicos que não são do PMM? Para tanto desmembrou-se tal objetivo em três partes fundamentais: Definir as principais competências médicas para a atenção básica a partir das Diretrizes Curriculares Nacionais (DCN) de 
Medicina; Verificar quais competências são mobilizadas mais adequadamente pelos médicos que são do PMM e que não são do PMM; Havendo diferenças na mobilização destas competências entre médicos que são do PMM e médicos que não são do PMM, analisar quais são as competências que são melhor mobilizadas por região do Brasil.

\section{Aspectos Conceituais e}

\section{MetodolóGicos}

A construção teórica priorizou três eixos interdependentes partindo inicialmente das múltiplas possibilidades de construtos relacionadas a temática das competências, seguido por um apanhado histórico da construção do SUS, perpassando pela Estratégia de Saúde da Família até a entrada do Programa Mais Médicos enquanto uma estratégia interministerial e por fim são apresentadas as peculiaridades do trabalho médico, centrando-se na construção histórico-social deste trabalho.
A temática da competência é a base que estrutura e envolve todos os demais componentes deste estudo. Para que exista a entrega de cada uma das competências médicas é preciso que vários elementos se conectem, começando pela formação educacional a que o indivíduo teve acesso, junto ao conhecimento social por ele apreendido bem como pela experiência acumulada, que serão fundamento para o arcabouço de conhecimentos, habilidades e atitudes que o indivíduo terá a sua disposição quando da ocorrência das situações.

Quanto tem-se as situações o médico precisará assumir de responsabilidade, ou seja, responder por sua ação em seu campo de atuação, observando o contexto que se apresenta com aquela dada situação e que interfere em quais recursos, sejam materiais, informacionais ou de conhecimento social e formal ele mobilizará. Junto a isso, o médico precisará reunir e convergir uma rede de atores que se façam relevantes para aquela situação determinada e transferir conhecimentos por esta rede.

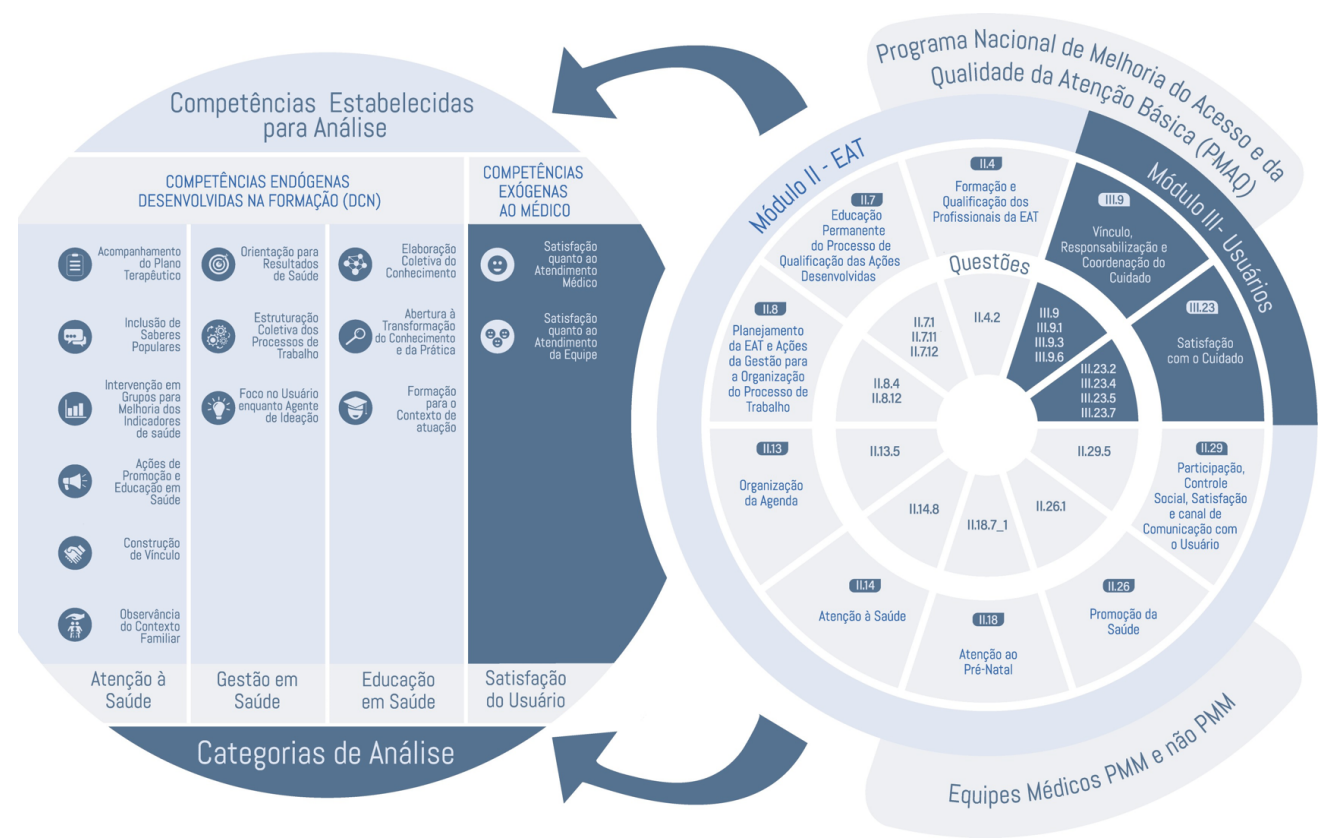

Fonte: elaborado pela autora. 
Quadro 1 - Síntese do Percurso Metodológico

\begin{tabular}{|c|c|}
\hline Item & Opção deste Estudo \\
\hline $\begin{array}{l}\text { Quanto à natureza da } \\
\text { pesquisa }\end{array}$ & Pesquisa Aplicada \\
\hline $\begin{array}{l}\text { Quanto à forma de } \\
\text { abordagem do problema }\end{array}$ & Quantitativa \\
\hline $\begin{array}{l}\text { Quanto aos fins da } \\
\text { pesquisa }\end{array}$ & Descritiva \\
\hline $\begin{array}{l}\text { Quanto aos procedimentos } \\
\text { técnicos }\end{array}$ & Pesquisa bibliográfica, pesquisa documental e survey \\
\hline Unidade de Análise & $\begin{array}{l}\text { Equipes de Atenção Básica que possuem médicos do PMM e Equipes de } \\
\text { Atenção Básica que não possuem médicos do PMM }\end{array}$ \\
\hline Universo & Módulo II: 29.778 equipes/Módulo III: 65.535 usuários \\
\hline Amostra & Módulo II: 27.086 equipes/Módulo III: 58.875 usuários \\
\hline Coleta de dados & $\begin{array}{l}\text { Dados secundários do Instrumento de Coleta de Avaliação Externa do } \\
\text { PMAQ }\end{array}$ \\
\hline Testes realizados & Qui-quadrado e Teste $\mathrm{t}$ \\
\hline Categorias de Análise & $\begin{array}{l}\text { Atenção à Saúde; Gestão em Saúde; Educação em Saúde, Satisfação do } \\
\text { Usuário }\end{array}$ \\
\hline Competências Analisadas & $\begin{array}{l}\text { Acompanhamento do Plano Terapêutico; Inclusão de Saberes } \\
\text { Populares; Intervenção em Grupos para a Melhoria dos Indicadores de } \\
\text { Saúde; Ações de Promoção e Educação em Saúde; Construção de } \\
\text { Vínculo; Observância do Contexto Familiar; Orientação para Resultados } \\
\text { de Saúde; Estruturação Coletiva dos Processos de Trabalho; Foco no } \\
\text { Usuário enquanto Agente de Ideação; Elaboração Coletiva do } \\
\text { Conhecimento; Abertura à Transformação do Conhecimento e da } \\
\text { Prática; Formação para o Contexto de Atuação; Satisfação quanto ao } \\
\text { Atendimento Médico; Satisfação quanto ao Atendimento da Equipe. }\end{array}$ \\
\hline $\begin{array}{l}\text { Variáveis utilizadas para a } \\
\text { análise das competências } \\
\text { definidas }\end{array}$ & $\begin{array}{l}\text { II.4.2; II.7.1; II.7.11; II.7.12; II.8.4; II.8.12; II.13.5; II.14.8; II.18.7_1; } \\
\text { II.26.1; II.29.5; III.9; III.9.1; III.9.3; III.9.6; III.23.2; III.23.4; III.23.5; } \\
\text { III.23.7 }\end{array}$ \\
\hline
\end{tabular}

Fonte: Elaborado pela autora.

O segundo campo de análise deste referencial e que está sobremaneira alicerçado e envolvido pelas competências é as construções dispostas sobre o Programa Mais Médicos e a sua inserção no SUS. 0 percurso metodológico está expresso na figura 1 , que apresenta as dimensões estudadas.

Para a análise dos dados realizou-se através do SPSS o teste do Qui-Quadrado $\left(X^{2}\right)$ para todas as variáveis, e para as variáveis que apresentaram uma escala likert com possibilidade de encontrar a média das respostas, utilizou-se o teste $t$.

\section{Resultados e Conclusões}

Os principais resultados encontrados a partir da análise dos dados estão a seguir no quadro-síntese que expressa os resultados por competência analisada (quadro 2). 
Quadro 2 - Síntese dos Resultados Encontrados por Competência Analisada

\begin{tabular}{|c|c|c|}
\hline $\begin{array}{l}\text { Categoria de } \\
\text { Análise }\end{array}$ & $\begin{array}{c}\text { Competência } \\
\text { Analisada }\end{array}$ & Síntese dos Resultados \\
\hline \multirow{6}{*}{$\begin{array}{l}\text { Atenção à } \\
\text { Saúde }\end{array}$} & $\begin{array}{l}\text { Acompanhamento } \\
\text { do Plano } \\
\text { Terapêutico }\end{array}$ & $\begin{array}{l}\text { Índice baixo de entrega da competência para as duas } \\
\text { equipes, mostrando a necessidade de melhorar as formas } \\
\text { de acompanhamento do plano terapêutico. Região Sudeste } \\
\text { apresenta melhores resultados para as equipes que não } \\
\text { possuem médicos do PMM. }\end{array}$ \\
\hline & $\begin{array}{c}\text { Inclusão de Saberes } \\
\text { Populares }\end{array}$ & $\begin{array}{l}\text { Índice baixo de entrega da competência, demonstrando a } \\
\text { necessidade de tornar os agentes que possuem estes } \\
\text { saberes parte do processo. Região Norte apresenta } \\
\text { melhores resultados para as equipes que possuem médicos } \\
\text { do PMM. }\end{array}$ \\
\hline & $\begin{array}{l}\text { Intervenção em } \\
\text { Grupos para } \\
\text { Melhoria dos } \\
\text { Indicadores de } \\
\text { Saúde }\end{array}$ & $\begin{array}{l}\text { Poucas ações apresentaram índices mais altos de } \\
\text { realização, de forma geral as duas equipes precisam tratar } \\
\text { esta competência com maior pró-atividade em sua } \\
\text { execução. Região Sul apresenta os melhores resultados com } \\
\text { diferença pequena entre as duas equipes. }\end{array}$ \\
\hline & $\begin{array}{l}\text { Ações de Promoção } \\
\text { e Educação em } \\
\text { Saúde }\end{array}$ & $\begin{array}{l}\text { Índices baixos de entrega desta competência para as duas } \\
\text { equipes, demonstrando que é preciso maior entrega já que } \\
\text { esta competência interfere diretamente na prevenção de } \\
\text { doenças. Região Sudeste apresenta os melhores resultados } \\
\text { para as equipes que não possuem médicos do PMM. }\end{array}$ \\
\hline & $\begin{array}{l}\text { Construção de } \\
\text { Vínculo }\end{array}$ & $\begin{array}{l}\text { Excelente resultado para as duas equipes quanto a entrega } \\
\text { desta competência. Região Nordeste apresenta os } \\
\text { melhores resultados para as equipes que não possuem } \\
\text { médicos do PMM. }\end{array}$ \\
\hline & $\begin{array}{l}\text { Observância do } \\
\text { Contexto Familiar }\end{array}$ & $\begin{array}{l}\text { Resultado que sugere grande atenção pelos baixos índices } \\
\text { de atendimento para as duas equipes. Região Sul apresenta } \\
\text { melhores resultados para as equipes que não possuem } \\
\text { médicos do PMM. }\end{array}$ \\
\hline \multirow{3}{*}{$\begin{array}{l}\text { Gestão em } \\
\text { Saúde }\end{array}$} & $\begin{array}{c}\text { Orientação para } \\
\text { Resultados de Saúde }\end{array}$ & $\begin{array}{l}\text { Possibilidade de melhoria de entrega desta competência } \\
\text { para as duas equipes. Região Sudeste apresenta melhores } \\
\text { resultados para as equipes que não possuem médicos do } \\
\text { PMM. }\end{array}$ \\
\hline & $\begin{array}{l}\text { Estruturação } \\
\text { Coletiva dos } \\
\text { Processos de } \\
\text { Trabalho }\end{array}$ & $\begin{array}{l}\text { Alto índice de mobilização desta competência para as duas } \\
\text { equipes. Região Norte apresenta melhores resultados para } \\
\text { as equipes que não possuem médicos do PMM. }\end{array}$ \\
\hline & $\begin{array}{l}\text { Foco no Usuário } \\
\text { Enquanto Agente de } \\
\text { Ideação }\end{array}$ & $\begin{array}{l}\text { Alto índice de mobilização desta competência para as duas } \\
\text { equipes. Região Sul apresenta os melhores resultados para } \\
\text { as equipes que não possuem médicos do PMM. }\end{array}$ \\
\hline \multirow{2}{*}{$\begin{array}{l}\text { Educação em } \\
\text { Saúde }\end{array}$} & $\begin{array}{c}\text { Elaboração Coletiva } \\
\text { do Conhecimento }\end{array}$ & $\begin{array}{l}\text { Altos índices de entrega para esta competência. Região } \\
\text { Sudeste apresenta os melhores índices para as equipes que } \\
\text { não possuem médicos do PMM. }\end{array}$ \\
\hline & $\begin{array}{l}\text { Abertura à } \\
\text { Transformação do } \\
\text { Conhecimento e da } \\
\text { Prática }\end{array}$ & $\begin{array}{l}\text { Baixa entrega para as duas variáveis analisadas. Região Sul } \\
\text { apresenta os melhores resultados para as equipes que não } \\
\text { possuem médicos do PMM. }\end{array}$ \\
\hline
\end{tabular}




\begin{tabular}{|c|c|c|}
\hline & $\begin{array}{l}\text { Formação para o } \\
\text { Contexto de } \\
\text { Atuação }\end{array}$ & $\begin{array}{l}\text { Competências com os piores índices de entrega para a } \\
\text { categoria. Região Sudeste apresenta os melhores índices } \\
\text { para as equipes que não possuem médicos do PMM. }\end{array}$ \\
\hline \multirow{2}{*}{$\begin{array}{l}\text { Satisfação do } \\
\text { Usuário }\end{array}$} & $\begin{array}{l}\text { Satisfação quanto ao } \\
\text { Atendimento } \\
\text { Médico }\end{array}$ & $\begin{array}{l}\text { Alta entrega desta competência para as duas equipes. } \\
\text { Região Sul apresenta os melhores resultados para as } \\
\text { equipes que não possuem médicos do PMM. }\end{array}$ \\
\hline & $\begin{array}{l}\text { Satisfação quanto ao } \\
\text { Atendimento da } \\
\text { Equipe }\end{array}$ & $\begin{array}{l}\text { Competência com entrega adequada para as duas equipes. } \\
\text { Região Sul apresenta os melhores resultados para as } \\
\text { equipes que não possuem médicos do PMM. }\end{array}$ \\
\hline
\end{tabular}

Fonte: Elaborado pela autora.

O estudo das competências permitiu lançar luz sobre aspectos relacionados às exigências e necessidades de atenção à saúde de um conjunto de profissionais com suas respectivas competências nem sempre associadas ao que é esperado em sua atuação cotidiana. O debate sobre as competências, que possui em sua essência a busca pelo alinhamento dos conhecimentos, habilidades e atitudes de um determinado profissional ao que ele efetivamente "entrega", encontra no âmbito da saúde, em particular no campo da atenção primária, uma expressão cristalina dos desafios e dificuldades que tal conceito enfrenta em termos de sua aplicação e exequibilidade.

Com efeito, a inquietação inicial visava compreender se havia diferenças na mobilização de competências quando do exercício da profissão de médicos que atuam no PMM e médicos que não atuam PMM sob a lente dos conhecimentos, habilidades e atitudes requeridas do egresso de medicina pelas DCNs do curso. Definiram-se treze competências-chave para os médicos da atenção básica. Tais competências reúnem também em sua essência os princípios do Programa de Saúde da Família, quais sejam, primeiro contato, coordenação, longitudinalidade, abordagem familiar, integralidade e o enfoque comunitário. Definiram-se ainda três categorias para abarcar as competências tomadas como endógenas (Atenção à Saúde, Gestão em Saúde e Educação em Saúde) e uma categoria para abarcar as competências tomadas como exógenas (Satisfação do Usuário).

Os resultados encontrados demonstram que entre as categorias de análise a que apresentou o pior resultado para a mobilização das competências analisadas foi Atenção à Saúde. Isso porque dentre as competências-chave verificadas apenas uma Construção de Vínculo - apresentou entrega satisfatória. Intervenção em Grupos para Melhoria dos Indicadores de Saúde foi a competência que apresentou resultados intermediários de entrega se comparada as demais competências da categoria. Acompanhamento do Plano Terapêutico, Inclusão de Saberes Populares, Ações de Promoção e Educação em Saúde bem como Observância do Contexto Familiar apresentaram os piores índices de atingimento dentro da categoria e na comparação com as demais competências de outras categorias também.

A categoria que apresenta o segundo melhor resultado de mobilização das competências-chave analisadas é a Categoria Satisfação do Usuário. Isso porque a competência Satisfação quanto ao Atendimento Médico apresenta bons resultados e a categoria Satisfação quanto ao Atendimento da Equipe apresenta ótimos resultados quanto à sua mobilização. A categoria que melhor incorpora os aspectos das competências analisadas é a Gestão em Saúde. Isso porque todas as competências analisadas para esta categoria, quais sejam, Orientação para Resultado de Saúde, Estruturação Coletiva dos Processos de Trabalho e Foco no Usuário enquanto Agente de Ideação apresentam excelentes mobilizações.

Observa-se ainda que pelos resultados por região é possível demonstrar quais estão mobilizando melhor cada uma das competências, o que fornece subsídio para que as equipes destas regiões tracem planos de ação para consolidar tais melhorias. As correlações entre competência e regiões que atingiram os melhores resultados para cada competência foram: Acompanhamento do Plano Terapêutico, região 
Sudeste; Inclusão de Saberes Populares, região Norte; Intervenção em Grupos para Melhoria dos Indicadores de Saúde, região Sul; Ações de Promoção e Educação em Saúde, região sudeste; Construção de Vínculo, região nordeste; Observância do Contexto Familiar, região Sul; Orientação para Resultados de Saúde, região Sudeste; Estruturação Coletiva dos Processos de Trabalho, região Norte; Foco no Usuário enquanto Agente de Ideação, região Sul; Elaboração Coletiva do Conhecimento, região Sudeste; Abertura à Transformação do Conhecimento e da Prática, região Sul; Formação para o Contexto de Atuação, região Sudeste; Satisfação quanto ao Atendimento Médico, região Sul; Satisfação quanto ao Atendimento da Equipe, região Sul.

Quanto aos resultados das equipes que possuem médicos do PMM e das equipes que não possuem médicos do PMM, de forma comparativa, é possível observar que, apesar de grande parte das variáveis analisadas apresentarem diferença significativa para os testes de Qui-quadrado, de maneira aplicada ao contexto dos eventos enquanto inteligência prática assumida para a entrega das competências analisadas, depreende-se que as diferenças percentuais são bem pequenas para a enorme parte das variáveis analisadas e todas sempre acompanham curvas muito similares de resultados.

O PMM tem bons elementos para inferir que o programa dentro do seu eixo de Educação tem apresentado transformações curriculares, bem como que os médicos que estiveram no programa nos ciclos analisados apresentaram excelentes resultados de forma comparativa. Isto porque apesar de percentualmente as equipes com médicos do PMM demonstrarem resultados um pouco inferiores as equipes que não possuem médicos do PMM, há de que se considerar que para além de serem médicos com formação baseada em outras competências, são indivíduos que haviam acabado de chegar em um país diferente, com aspectos culturais diferentes e com uma língua diferente. $E$, para além destes fatores, o espaço temporal de análise é relativo aos ciclos iniciais do programa, o que retoma ao já exposto no referencial teórico quanto à desconfiança coletiva da população que ainda havia quanto à qualidade do cuidado que seria ofertado pelos médicos do PMM. Acredita-se que ciclos posteriores de pesquisa utilizando dados comparativos do PMAQ apresentarão resultados ainda melhores para os médicos do PMM.

Quanto à formação médica brasileira, o que se pode inferir é que as mudanças feitas nas diretrizes curriculares apresentam consonância com as necessidades da atenção básica. Isso porque as DCNs atuais estão conectadas aos princípios do SUS e do PSF. Quando de sua análise quanto à mobilização das competências-chave, observa-se que os médicos que hoje atuam na atenção básica ainda apresentam lacunas na entrega das mesmas, o que em grande medida se explica pela não formação sobre estas bases e aponta para a necessidade de melhora na mobilização da competência Formação para o Contexto de Atuação. O que se constata, portanto, é que a formação em cursos que tragam a abordagem da atenção básica para estes médicos que já se encontram em atuação nas equipes de saúde da família é urgente e primordial para a melhoria da mobilização das demais competências.

Quanto o direcionamento das avaliações da atenção básica pela linha de entrega dos conhecimentos, habilidades e atitudes traçados pelas DCNs de medicina e aqui traduzidas em competência, faz-se uma proposição de que sejam formulados instrumentos de avaliação preparados e direcionados para a análise das mesmas, de forma que não sejam preciso realizar correspondências com outros instrumentos de avaliação que não tem como função primeira a análise de competência e acaba por não fornecer tantos indícios quanto seriam interessantes se obter tanto para uma análise quantitativa, quanto para uma análise qualitativa.

O que o estudo observou é que não há sentido em se formar médicos baseado em um currículo voltado para competências se não se avalia a entrega destes médicos quanto à mobilização da inteligência prática nas situações que Ihes são apresentadas no cotidiano do trabalho por meio também da análise de competência. Sendo assim, a proposta de construção do instrumento é correspondente a conhecimentos, habilidades e atitudes dispostos na DCNS e que devem ser apreendidos em um questionário sempre voltado a ação em experiências passadas, ou seja, o questionário deve expressar 
exemplos de mobilizações adequadas de cada uma das competências de modo a verificar qual a entrega relativa que o médico teve nesta dada situação.

Em síntese, o acerto do PMM vai além do provimento emergencial, mas exige ajustes em diferentes esferas para torná-lo efetivamente capaz de gerar mais saúde para todos e todas.

\section{REFERÊNCIAS BIBLIOGRÁFICAS}

(1) Coelho, E. C. As Profissões Imperiais: Medicina, Engenharia e Advocacia no Rio de Janeiro, 1822-1930. Rio de Janeiro: Editora Record, 1999. 241 p.

(2) Nascimento, J. G. S. Mobilizando competências: Mais Médicos ou Mais Saúde? Belo Horizonte: FACE/UFMG, 2018. 174 p. (tese de doutorado).

\section{ABSTRACT}

This article aims to clarify if there are differences in mobilization of skills when the practice of the profession among doctors of the Medical Program (PMM) and physicians who are not of the PMM. Taking as reference the prospects of jurisdiction brought, the PMM deployment history in the health system and the historical buildings of the medical profession, the definition of thirteen key competences for doctors who work on Attention 101. To this end, nineteen variables were selected from the instrument for external evaluation of the national programme for improving access and quality of basic care to analyze the skills established, on which were carried out tests of Chi-square and t-test when possible, with a sample of 27,086 teams and 78,875 respondent users. It was noted that for all the skills analysed there was little difference between the results of mobilisation of the teams that have doctors that are from the PMM and doctors who are not, especially in the South and Southeast regional analyses, with a slight preponderance of positive results brought by doctors of the teams that are not from the PMM. This can be well explained, since the sample refers to the initial cycles of PMM and, more than that, are being analyzed by the lens powers of National curriculum guidelines, which allows to infer about how the results of the doctors of the teams that have doctors in the PMM are satisfactory.

Keywords: Competences, SUS, PMM. 